\title{
Conciliação Trabalho-Família na Profissão Médica: Um Estudo Exploratório
}

\author{
Work-Family Balance Within the Medical Profession: \\ An Exploratory Study
}

\author{
Pedro AFONSO $\varangle^{1}$, Olga Vaz ALEIXO², Rute Vaz ALEIXO3 ${ }^{3}$, Diogo J. F. de CARVALHO ${ }^{4}$, José Augusto SIMÕES5,6 \\ Acta Med Port 2019 Nov;32(11):697-705 - https://doi.org/10.20344/amp.11997
}

\begin{abstract}
RESUMO
Introdução: Este estudo propôs-se caraterizar e avaliar a conciliação trabalho-família na profissão médica em Portugal.

Material e Métodos: Este é um estudo observacional, transversal e exploratório de uma amostra de 181 médicos sócios da Associação dos Médicos Católicos Portugueses. Foi aplicado um questionário de resposta múltipla e valoração qualitativa, por forma a avaliar caraterísticas socioeconómicas, laborais e a conciliação trabalho-família. Foram realizadas análises descritiva e de regressão linear. Resultados: Cerca de $40 \%$ dos médicos inquiridos avaliam negativamente a conciliação trabalho-família no sector privado. Já para o Serviço Nacional de Saúde, são $73 \%$ os médicos inquiridos que avaliam negativamente a conciliação trabalho-família no sector público. Verificou-se que mais de metade dos inquiridos (56\%) tinha uma carga horária superior à que considera danosa à sua conciliação trabalho-família, sendo que a grande maioria trabalhava no limite ou em excesso de carga horária. Os dados obtidos permitiram associar maior carga horária com fazer urgências, com a idade e ser do sexo masculino. Foi ainda observado que maior carga horária não está associada a ter filhos ou ser casado.

Discussão: No nosso estudo, as três medidas de conciliação trabalho-família que os participantes consideraram ser as mais importantes foram a possibilidade de flexibilizar o horário, trabalhar a tempo parcial e reduzir temporariamente o horário de trabalho (por exemplo, devido a assistência à família). Estes aspetos poderão explicar as diferenças encontradas na avaliação da conciliação trabalho-família entre o sector público e o sector privado.

Conclusão: A profissão médica pelas suas características de exigência coloca os médicos numa situação particular de risco para alcançarem uma adequada conciliação trabalho-família. Os resultados do nosso estudo apontam para uma insatisfação dessa conciliação, sendo que essa insatisfação é mais marcada no sector público, tendencialmente associada ao excesso de carga horária semanal.
\end{abstract}

Palavras-chave: Conciliação Trabalho-Família; Excesso de Trabalho; Médicos, Satisfação no Trabalho

\section{ABSTRACT}

Introduction: The aim of this study is to characterize and assess work-family balance within the medical profession in Portugal.

Material and Methods: This cross-sectional and exploratory study analyzed a sample of 181 doctors who are members of the Portuguese Catholic Doctors' Association. A qualitative survey with multiple-choice questions was applied in order to assess socioeconomic and working conditions as well as work-family balance. Descriptive and linear regression analyses were carried out.

Results: Nearly $40 \%$ of the surveyed doctors negatively assessed the work-family balance within the private sector. As for the Portuguese National Health System, $73 \%$ negatively assessed the work-family balance within the public sector. More than half of those surveyed (56\%) worked more hours than what they considered as harmful for their work-family balance and the vast majority was working at the limit or overtime. Data collected enabled us to associate a heavier workload with working in the emergency room, age and men. Moreover, it was observed that working more hours was not linked to having children or being married.

Discussion: In our study, the three measures of work-family balance that the participants considered to be the most important were the possibility of flexible scheduling, part-time work and temporarily reducing working hours (e.g. for family assistance). These aspects may explain the differences found in the assessment of work-family balance between the public and private sector.

Conclusion: Due to the demanding nature of the medical profession, doctors are placed into a particularly risky situation in order to achieve a suitable work-family balance. The results of our study indicate a general dissatisfaction regarding this balance - special in the public sector — which is mainly associated with excessive weekly working hours.

Keywords: Family; Job Satisfaction; Physicians; Portugal; Work-Life Balance; Work Schedule Tolerance; Workload

\section{INTRODUÇÃO}

Aestrutura familiar patriarcal que existia no século XX, na qual o pai era o principal garante do sustento económico da família, alterou-se profundamente. A mulher, outrora dedicada quase exclusivamente ao trabalho doméstico e à educação dos filhos, tem hoje um papel ativo no mundo laboral, ambicionando legitimamente a uma carreira profissional. ${ }^{1}$
Situação particularmente relevante na Medicina, em que se assistiu nos últimos anos a um aumento do número de alunas no curso de medicina. Inicialmente nas entradas para as Escolas Médicas, em 2000 a percentagem de mulheres no curso de Medicina já era de $69 \% .^{2}$ A que naturalmente se seguiu as entradas para as especialidades médicas, em $2005,76,1 \%$ dos internos do primeiro ano de Medicina

3. Médica Interna do Ano Comum. Centro Hospitalar de Trás-os-Montes e Alto Douro. Vila Real. Portugal.

4. AESE Business School. Lisboa. Portugal.

5. Faculdade de Ciências Médicas. Universidade da Beira Interior. Covilhã. Portugal.

6. CINTESIS - Centro de Investigação em Tecnologias e Serviços de Saúde. Porto. Portugal.

$\triangle$ Autor correspondente: Pedro Afonso. pedroafonso@medicina.ulisboa.pt

Recebido: 28 de fevereiro de 2019 - Aceite: 06 de maio de 2019 | Copyright $\odot$ Ordem dos Médicos 2019 
Geral e Familiar eram mulheres, ${ }^{3}$ e, em 2017, 54,5\% dos inscritos na Ordem dos Médicos são do sexo feminino. ${ }^{4}$ Porém, a exigência da atividade profissional pode originar desigualdades sociais nas mulheres, devido à multiplicidade de tarefas que estas cumprem, designadamente ao nível familiar. ${ }^{1}$

A sociedade mudou, existindo um envelhecimento da população e uma diminuição da taxa de natalidade, com o nosso país em 2016 a registar uma das taxas de fertilidade mais baixas da União Europeia (1,36 nados-vivos por mulher). ${ }^{5}$ Mas as mudanças fizeram-se sentir também ao nível da própria estrutura da família, já que tem havido um aumento do número de famílias monoparentais, resultante do crescente número de divórcios, tendo-se verificado em 2017 um rácio de divórcios por cada 100 casamentos de $64 \%{ }^{6}$

O trabalho e a família constituem duas áreas fundamentais da sociedade, estando reciprocamente interdependentes: uma enriquece a outra e vice-versa. A conciliação trabalho-família pode ser definida como a existência de uma boa relação entre o contexto profissional e familiar, enquanto ambientes que emanam exigências às quais o indivíduo é capaz de responder simultânea e adequadamente, sem perdas, decorrentes da interferência de um sobre o outro. ${ }^{7,8}$

As dificuldades na conciliação trabalho-família originam diversas tensões quer no seio da vida familiar quer ainda nas próprias empresas. Por exemplo, originando conflitos no relacionamento conjugal devido ao excesso de carga horária, criando dificuldades na progressão da carreira, impedindo que as mulheres assumam determinadas responsabilidades profissionais pelo facto de poderem engravidar ou de terem filhos menores, etc. ${ }^{9,10}$ Este aspeto é reforçado pelo facto de vivermos numa sociedade competitiva, que valoriza a carreira profissional e o sucesso económico, como fator de prestígio social e de realização individual.

Para que haja uma boa conciliação entre trabalho e a família é importante a implementação de medidas prófamiliares que de acordo com Flaquer ${ }^{11}$ podem ser definidas "Como um conjunto de medidas públicas destinadas a fornecer recursos a pessoas com responsabilidades familiares para que possam desempenhar nas melhores condições possíveis as tarefas e atividades delas derivadas, em especial a atenção para com os filhos dependentes....as medidas de apoio às famílias são aquelas que facilitam às pessoas com encargos familiares um melhor desempenho das suas responsabilidades e que não comportam penalização económica, social e profissional". ${ }^{11}$

Existem um conjunto de medidas que podem ser aplicadas pelas organizações que facilitam a concliliação trabaIho-família. Por exemplo, a implementaçã o de programas de férias para crianças e programas de acompanhamento das crianças nos seus tempos livres em complementaridade com a escola, com o objectivo de se ultrapassar a dificuldade que pais/mães trabalhadores(as) sentem de não ter onde deixar os seus filhos em segurança e sob adequada supervisão, a flexibilidade nos horários de trabalho permitindo, deste modo, cuidar de familiares idosos, a possibilidade de trabalhar a tempo parcial para acompanhar os filhos em idade pré-escolar, etc.

Alguns estudos evidenciaram uma associação negativa entre parentalidade e felicidade, revelando níveis mais baixos de felicidade entre os pais quando comparados com os sem filhos na maioria das sociedades industrializadas. Concetualizando a parentalidade como um fator stressor, que, no entanto, pode ser atenuado pelo apoio institucional. Assim, as diferenças de status parental na felicidade são menores em países que fornecem mais recursos e apoio às famílias. Pelo que, políticas familiares mais generosas, particularmente tempo de folga pago e subsídios para cuidar de crianças, estão associadas a menores disparidades de felicidade entre pais e não-pais. Além disso, as políticas que aumentam a felicidade parental não reduzem a felicidade dos não-pais. ${ }^{12}$

Para além dos indivíduos, as próprias organizações tendem a lucrar com a implementação de medidas que favoreçam a conciliação trabalho-família, sobretudo porque, nesses casos, os trabalhadores se sentem mais comprometidos com a organização, ${ }^{13-15}$ e mais motivados o que conduz a um aumento dos níveis de produtividade..$^{16,17}$

Importa ainda referir que as empresas que adotem medidas de conciliação trabalho-família, promovem a satisfação dos seus trabalhadores, levando a uma redução de conflitos laborais e a uma boa imagem da própria empresa, através de divulgação de boas práticas de responsabilidade social. ${ }^{9,13,18}$

E a existência de condições nas empresas favoráveis à conciliação da vida laboral e familiar facilitam a coesão social, e promovem o trabalho da mulher, oferecendo melhores garantias para a sua realização profissional. ${ }^{19}$

As dificuldades de conciliação trabalho-família é um tema importante que deve merecer uma maior atenção das instituições de saúde públicas e privadas. Neste caso, os médicos devido às características da sua atividade profissional encontram-se particularmente em risco. ${ }^{20}$

O conflito trabalho-família (CTF) pode ser definido como uma forma de conflito entre papéis, observada quando as pressões provenientes do trabalho e da família se tornam, de algum modo, mutuamente incompatíveis. ${ }^{21} \mathrm{De}$ acordo com Greenhaus \& Beutell, ${ }^{21}$ os múltiplos papéis profissionais ou familiares que um trabalhador tem de desempenhar (por exemplo, como pai, mãe, cônjuge, função profissional técnica, administrador de empresa, etc.) competem entre si pelo tempo que o indíviduo tem disponível.

Convém sublinhar que o CTF é bastante prevalente na profissão médica, estando envolvidos vários fatores organizacionais e individuais. ${ }^{21,22}$ Perante a escassez de dados relativos à realidade portuguesa, torna-se importante compreender e analisar que práticas de conciliação do trabaIho-família estão a ser implementadas pelas instituições de saúde, relativamente à profissão médica. Além disso, será também relevante identificar e diferenciar um conjunto de medidas de conciliação trabalho-família a serem implementadas, de modo a melhorar a responsabilidade familiar do sector público e privado na área da saúde. 
O objetivo principal deste estudo foi caracterizar e avaliar a conciliação trabalho-família na profissão médica. Os objetivos secundários foram obter uma classificação pelos inquiridos de um conjunto de medidas apresentadas (nove no total). Por fim, houve ainda o objetivo de avaliar a classificação da conciliação trabalho família no Serviço Nacional de Saúde (SNS) comparativamente ao sector privado da saúde.

\section{MATERIAL E MÉTODOS}

Este é um estudo observacional, transversal e exploratório. A amostra foi recolhida através das respostas online a um questionário elaborado para o efeito, através de convite enviado por email aos associados da Associação dos Médicos Católicos, recorrendo a uma hiperligação personalizada criada pelo site Surveymonkey ${ }^{\circledR}$. No convite dirigido aos participantes, foram referidos os objectivos do estudo, foi mencionado que estaria garantida a confidencialidade dos dados e que os resultados deste inquérito seriam tratados em conjunto e posteriormente divulgados publicamente. A participação no inquérito foi voluntária.

Para a realização deste estudo foi obtida autorização da direção nacional da Associação dos Médicos Católicos Portugueses (AMCP) para utilização da sua base de dados, constituída por um universo de 530 médicos seus associados.

O questionário era constituído por perguntas fechadas, de resposta múltipla e de valoração qualitativa, a fim de facilitar a resposta e a avaliação.

Como dados de caracterização foi questionado: idade, sexo, estado civil, número de filhos e de idosos dependentes a cargo, região onde trabalha, sector de atividade, especialidade, número de dias e horas de trabalho semanal, trabalho além do horário, serviço de urgência. Foi ainda questionada a opinião acerca de carga horária semanal a partir da qual há claro prejuízo na conciliação trabalhofamília, bem como a classificação de medidas de conciliação trabalho-família propostas no questionário.Também foi pedida a avaliação global da conciliação trabalho-família no Serviço Nacional de Saúde (SNS) e no sector privado da saúde. Neste caso, a escala de resposta possível foi: péssima, muito má e sofrível (agrupadas em avaliação "negativa"), nem boa nem má (considerada avaliação "neutra") e boa, muito boa e excelente (agrupadas em avaliação "positiva"). Por fim, foi solicitada a avaliação da satisfação global com a conciliação trabalho-família no caso pessoal, e se considera que a implementação de medidas que promovam a conciliação trabalho-família podem ajudar a aumentar a natalidade. A satisfação com a conciliação trabalhofamília foi medida numa escala ordinal de 1 a 5 , em que 1 corresponde a "Muito insatisfeito" e 5 a "Muito satisfeito".

A resposta a este inquérito foi voluntária e confidencial. Após receção do convite, os participantes aceitaram que os dados por si gerados fossem objeto de tratamento estatístico e divulgação científica.

Neste trabalho, foi efetuada uma análise descritiva dos resultados. Foram ainda, efetuadas análises de regressão linear múltipla. As análises de regressão pretendiam dar profundidade e perspetiva a alguns aspetos da análise descritiva, sem nenhuma pretensão de chegar a um modelo de 'equilíbrio geral' entre as múltiplas variáveis. Este é um estudo exploratório que pretende sobretudo dar pistas para o debate sobre a conciliação trabalho-família na profissão médica em Portugal, apresentando uma primeira evidência empírica.

Assim, optou-se por estimar apenas um modelo de regressão linear múltipla para a "carga horária semanal", em horas (varável dependente). Testaram-se diferentes especificações com variáveis explicativas (varáveis independentes), nomeadamente o número de filhos, e idade, para a qual se introduziu um termo quadrático para capturar a relação não linear expectável em teoria; também se incluíram variáveis binárias como o sexo, realizar serviço de urgência, a região geográfica, situação familiar, trabaIhar frequentemente em casa depois do horário de trabaIho e trabalhar apenas no SNS por confronto com trabalhar apenas no sector privado ou em ambos. Os coeficientes são estimados por OLS (método dos mínimos quadrados), utilizando erros padrão robustos para lidar com eventuais problemas de heteroscedasticidade.

As análises dos dados foram realizadas com o software estatístico EViews 6 para Windows e com o Microsoft Excel.

\section{RESULTADOS}

Obtiveram-se 181 respostas válidas, do total de 530 médicos da AMCP contactados, o que resulta numa taxa de resposta de $34,2 \%$.

A idade média da amostra obtida, pelos respondentes, foi 46,5 anos, com um desvio-padrão (DP) de 13 anos. A distribuição encontra-se descrita na Fig. 1. Verificou-se uma proporção muito próxima entre médicos com menos de 46 anos $(50,8 \%)$ e com 46 ou mais anos (49,2\%).

A restante caracterização sociodemográfica da amostra encontra-se na Tabela 1. A amostra é bastante equilibrada quanto ao sexo: $58,6 \%$ dos participantes eram do sexo feminino e $41,4 \%$ eram do sexo masculino. No perfil familiar, cerca de 3/4 dos inquiridos estavam casados, e a mesma porção de inquiridos reporta ter filhos (média de 2,5 filhos). Apenas $11,1 \%$ dos inquiridos têm familiares idosos a cargo; os não casados são, na sua grande maioria, solteiros. Os participantes trabalhavam maioritariamente no Porto e região Norte $(49,7 \%)$, Lisboa e Sul $(33,7 \%)$ e Coimbra e região Centro (10,5\%).

Da análise dos dados laborais, foi possível constatar que praticamente 3/4 dos indivíduos tinha uma especialidade médica, exercida no setor público ou em ambos os setores. Apenas $10,5 \%$ trabalha somente no sector privado. Neste grupo a maioria trabalha na área hospitalar. $\mathrm{Na}$ nossa amostra, $50,3 \%$ dos participantes faziam serviço de urgência.

A maioria dos respondentes declarou trabalhar cinco dias por semana, embora cerca de $25 \%$ trabalhassem seis dias. A carga horária média semanal da amostra foi de 46,8 


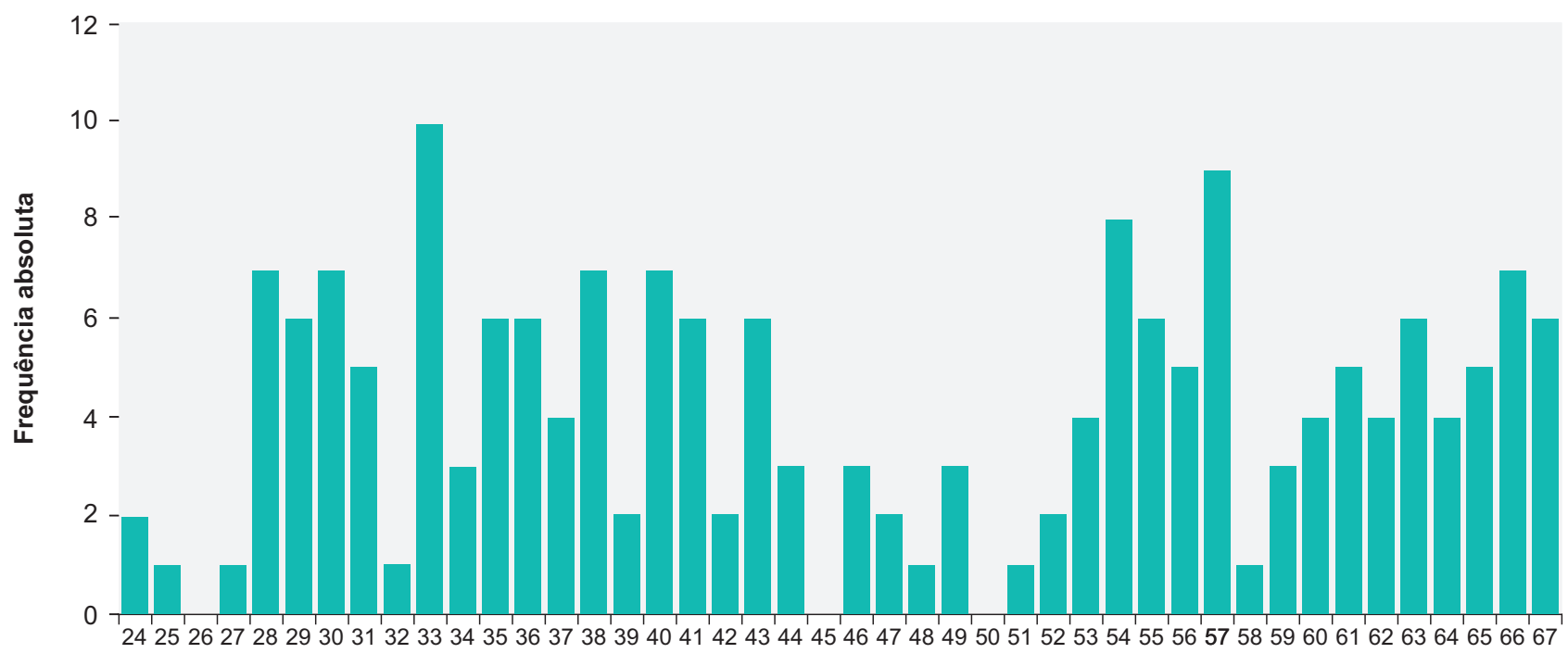

Idade, em anos

Figura 1 - Distribuição dos respondentes por idade

Tabela 1 - Caracterização sociodemográfica e satisfação conciliação trabalho-família

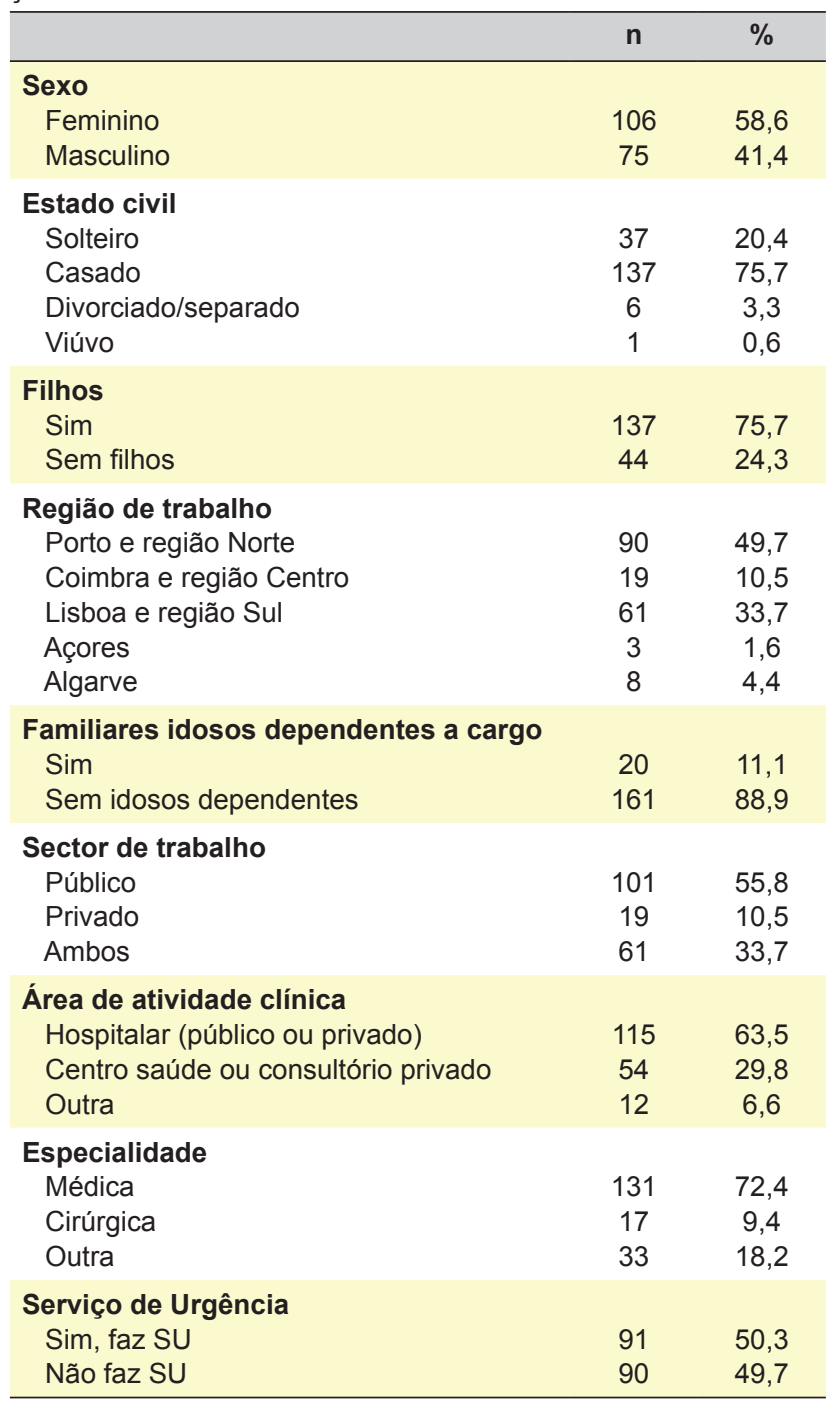

horas (DP 10,6) e uma distribuição próxima da normal. Uma percentagem superior a $60 \%$ declarou ter uma carga laboral acima das 40 horas semanais, conforme ilustrado na Fig. 2. Destes, quase metade afirma ainda trabalhar frequentemente em casa em assuntos profissionais, após de ter cumprido o horário de trabalho. De resto, se considerarmos toda a amostra, $74 \%$ dos participantes referem que também trabalham, frequentemente, em casa para além do horário. Tem particular interesse realçar ainda que $40 \%$ dos médicos afirmam trabalhar habitualmente 50 ou mais horas semanais.

A distribuição da amostra consoante o grau de satisfação com a conciliação trabalho-família encontra-se na Tabela 2. Pela sua análise verifica-se que a maioria dos médicos tinha uma opinião definida, sendo que $40 \%$ revelou estar insatisfeito ou muito insatisfeito com a conciliação trabalho-família, e $35 \%$ consideravam-se satisfeitos ou muito satisfeitos. Esta diferença de cinco pontos percentuais revelou-se significativa a um nível de significância estatística de $10 \%$, quando aplicado o respetivo teste de hipóteses à diferença de proporções.

\begin{tabular}{lcc}
\multicolumn{4}{l}{ Tabela 2 - Satisfação conciliação trabalho-família } \\
\hline Avaliação global & $\mathbf{n}$ & $\%$ \\
Muito insatisfeito & 11 & 6,1 \\
Insatisfeito & 63 & 34,8 \\
Nem satisfeito / Nem insatisfeito & 45 & 24,9 \\
Satisfeito & 56 & 30,9 \\
Muito satisfeito & 6 & 3,3 \\
Avaliação de acordo com o sector & Privado & SNS \\
Toda a amostra ( $=181)$ & & \\
Positiva & $25 \%$ & $10 \%$ \\
Negativa & $46 \%$ & $67 \%$ \\
Médicos que trabalham em ambos sectores $(\mathrm{n}=61)$ & \\
Positiva & $19 \%$ & $7 \%$ \\
Negativa & $40 \%$ & $73 \%$ \\
\hline
\end{tabular}




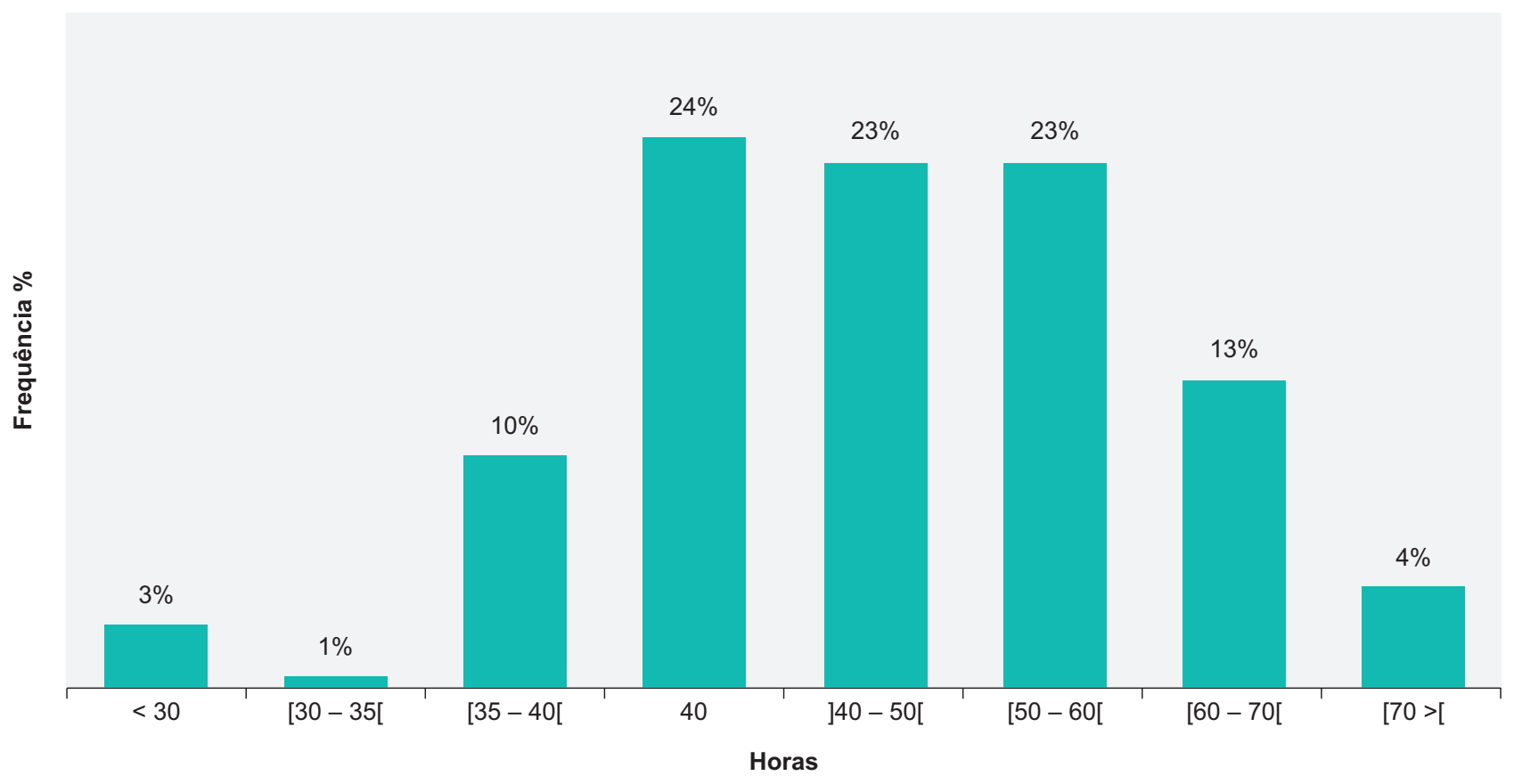

Figura 2 - Carga horária semanal

Cerca de $40 \%$ dos inquiridos avaliam negativamente a conciliação trabalho-família no sector privado. Já no caso do SNS, são $73 \%$ os médicos inquiridos que avaliam negativamente a conciliação trabalho-família no sector público. Não se verificaram diferenças significativas nos resultados se consideradas somente as respostas dos médicos que trabalhavam em ambos os setores, persistindo uma dualidade de opinião sobre esta temática.

Quando questionados sobre o limite máximo de carga horária semanal a partir do qual consideravam haver claro prejuízo na conciliação trabalho-família, verificou-se que $51 \%$ dos médicos considerou que trabalhar mais de
35 - 40 horas semanais implica claro prejuízo na conciliação trabalho-família, e $23 \%$ da amostra considera que esse limite será só a partir das 50 horas semanais, o que vai de encontro com a dualidade manifestada sobre satisfação global com a conciliação.

Relacionando a carga horária semanal real com a desejada (Fig. 3) pode-se verificar que $56 \%$ dos médicos têm uma carga horária superior à que consideram que causa dano claro à sua conciliação trabalho-família; ou seja, todos os que estão abaixo da linha de $45^{\circ}$. As observações na, ou muito próximas, da linha de $45^{\circ}$ indicam médicos com uma carga horária "no limite" do que consideram danoso (17\%).

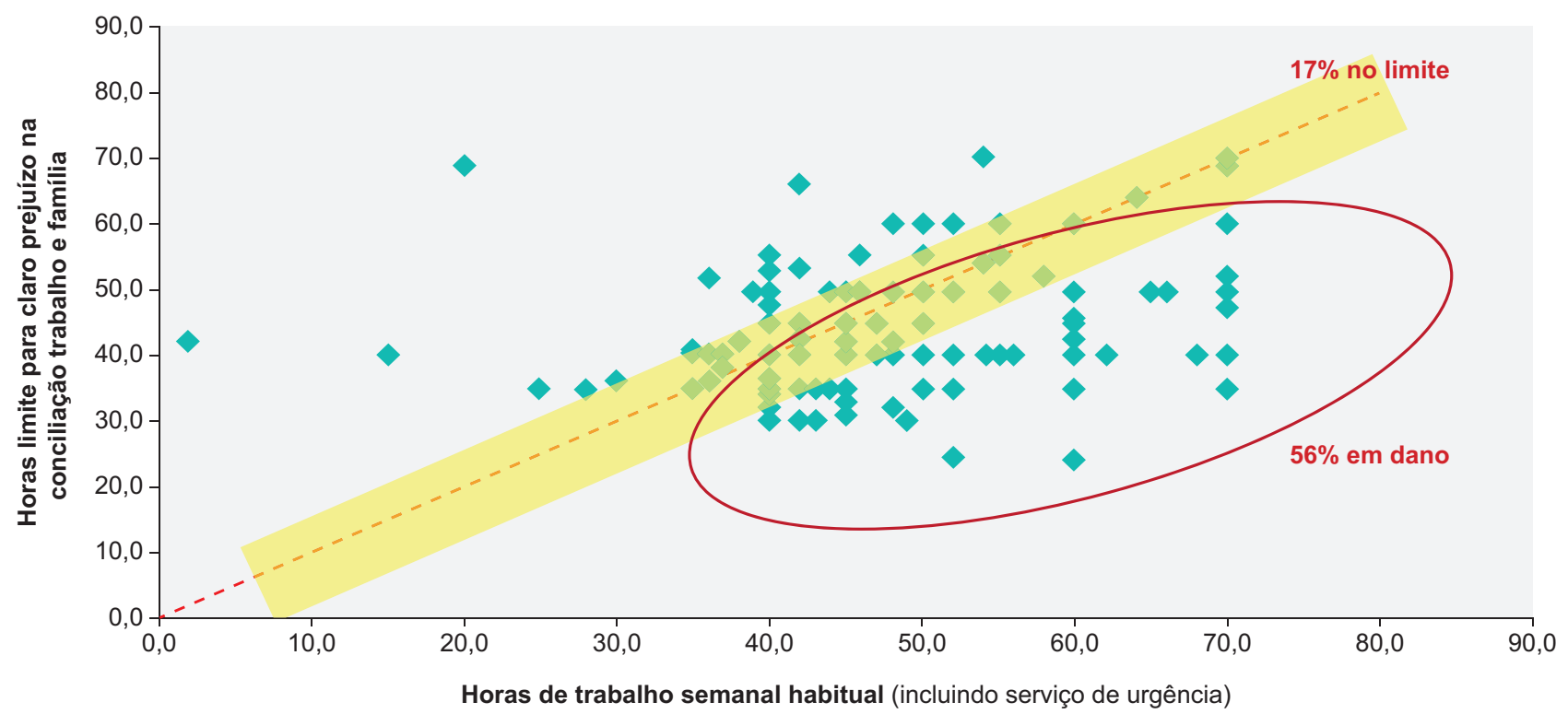

Figura 3 - Associação entre carga horária semanal real e desejada 
Tabela 3 - Análise de regressão linear múltipla para a carga horária semana (horas)

\begin{tabular}{|c|c|c|c|c|c|}
\hline & Coeficiente & Erro Padrão & Estatística $\mathrm{t}$ & Valor $p$ & \\
\hline Constante & 2,9619 & 12,1219 & 0,2443 & 0,8073 & \\
\hline Realizar serviço urgência = 1 & 6,2548 & 1,2598 & 4,9651 & 0,0000 & $* * *$ \\
\hline Homem $=1$ & 5,5549 & 1,3621 & 4,0781 & 0,0001 & *** \\
\hline SNS = 1 & $-2,1187$ & 1,4733 & $-1,4381$ & 0,1522 & \\
\hline Ter filhos $=1$ & 3,3852 & 2,2845 & 1,4818 & 0,1402 & \\
\hline Idade (anos) & 1,9346 & 0,5491 & 3,5234 & 0,0005 & $* * *$ \\
\hline$I_{\text {Iade }}^{2}$ (anos) & $-0,0218$ & 0,0061 & $-3,600$ & 0,0004 & *** \\
\hline Trabalho adicional em casa $=1$ & 2,6281 & 1,5185 & 1,7307 & 0,0853 & * \\
\hline Casado $=1$ & $-1,4276$ & 1,8952 & $-0,7533$ & 0,4523 & \\
\hline Número de filhos & $-0,7736$ & 0,6014 & $-1,2862$ & 0,2001 & \\
\hline Coeficiente de correlação $\left(R^{2}\right)$ & 0,3588 & & & & \\
\hline Coeficiente de correlação ajustado & 0,3210 & & & & \\
\hline Erro padrão da regressão & 8,7239 & & & & \\
\hline Estatística F (significância global) & 9,5107 & & & & \\
\hline Valor $p$ (estatística F) & 0,0000 & & & & \\
\hline
\end{tabular}

* significante a $10 \% ;{ }^{* * *}$ significante a $5 \%$.

As variáveis com a referência " $=1$ " são variáveis binárias que tomam o valor 1 se possuem essa característica, e zero em caso contrário. "SNS = 1" se o médico apenas trabalha no Serviço Nacional de Saúde e 0 se trabalha apenas no privado ou em ambos. "Trabalho adicional em casa = 1" se o médico, depois de ter cumprido o horário de trabalho, costuma frequentemente trabalhar em casa (trabalho relacionado com a profissão).

No modelo de regressão estimado com a "carga horária semanal" como variável dependente, incluíram-se como variáveis explicativas as que constam na Tabela 3.

Esta regressão sugere que, em média, mantendo tudo o resto constante (ceteris paribus), a carga horária aumenta com realização de serviço de urgência, pertencer ao sexo masculino, e com a idade (até aos 46 anos, pois depois tende a diminuir ligeiramente); mas diminui para os que trabalham apenas no SNS. Por sua vez, sugere a ausência de relação com variáveis como, por exemplo, o número de filhos, ou ser casado. Este modelo, relativamente simplificado, tem, no entanto, um ajustamento muito razoável, sendo que estas variáveis, quando introduzidas em conjunto, explicam cerca de $32 \%$ da variação da carga horária.

Em média, os inquiridos consideraram que todas as nove medidas de conciliação trabalho-família propostas são importantes, mas as relacionadas com a flexibilidade de horário de trabalho foram as consideradas mais importantes $(38 \%)$, seguida pela possibilidade de trabalho a tempo parcial $(20 \%)$.

A quase totalidade da amostra (97\%) considerou que a implementação de medidas promotoras da conciliação trabalho- família pode ajudar no aumento da natalidade, indo ao encontro da necessidade de se reverter a baixa taxa de natalidade do nosso país.

\section{DISCUSSÃO}

Consideramos que este estudo teve uma boa participação em termos de respostas de médicos jovens $(25-45$ anos) e experientes ( $45-65$ anos). A taxa de resposta de $34,2 \%$ do nosso inquérito enviado por email encontra-se dentro dos valores habitualmente obtidos para este tipo de instrumento de avaliação. ${ }^{23}$ No entanto, deve haver precaução na população para a qual se pretende inferir, visto que esta amostra só se poderia considerar razoavelmente representativa de toda a classe médica portuguesa se assumíssemos a hipótese de que ser membro da AMCP não reflectiria per se determinadas posições sobre a conciliação trabalho-família, expressas nas respostas ao questionário. Como não parece uma hipótese forte, é pouco seguro generalizar os resultados. Por conseguinte, este é um estudo sobretudo exploratório.

Com o modelo de carga horária foi possível estabelecer que, em média, mantendo tudo o resto constante:

Um médico que trabalha só no Serviço Nacional de Saúde trabalha, em média, menos duas horas semanais que um médico que trabalha em ambos os setores ou só no privado.

A carga horária está associada a fazer urgências, ao sexo masculino, a trabalhar frequentemente em casa depois do horário de trabalho e à idade. Maior carga horária está associada positivamente, como é natural, a fazer serviço de urgência.

Os participantes do sexo masculino trabalham mais 5,6 horas semanais do que os do sexo feminino. Dos que trabalham 60 ou mais horas, $66 \%$ são homens (versus $42 \%$ na amostra global). Alguns estudos demonstraram que as médicas com filhos passam mais tempo com a família do que os homens, ${ }^{21,22,24,25}$ tentando combinar a carreira médica com o cuidar dos filhos ou trabalhando a tempo parcial. ${ }^{26}$

Ser casado ou o número de filhos não parece afetar significativamente a carga horária. Na verdade, dos que trabalham 50 ou mais horas, $80 \%$ têm pelo menos um filho. Em todo o caso, ter filhos - um ou vários - parece aumentar a carga horária em relação aos que não os têm em 3,4 horas semanais, um valor forte e um pouco contraintuitivo, mas a debilidade da significância estatística poupa mais elaborações.

Há forte evidência para uma relação quadrática/côncava entre a idade e a carga horária. O modelo prevê que até aos 46 anos, em cada ano os médicos adicionam quase duas horas à sua carga horária semanal; a partir dessa idade, as 
horas de trabalho começam a diminuir, mas tão lentamente que podemos considerar que depois de atingir o máximo, virtualmente estagnam até ao fim da carreira profissional.

Verificou-se que a maioria dos participantes (56\%) tem uma carga horária superior à que considera danosa à sua conciliação trabalho-família, e $17 \%$ da amostra sente que trabalha no limite do que considera ser danoso. Portanto, $3 / 4$ dos inquiridos trabalham no limite ou em excesso de carga horária, prejudicando o equilíbrio entre as diversas dimensões da sua vida. Sublinhe-se que, de acordo com a Diretiva Europeia (2003/88/EC), o limite máximo da carga horária semanal é de 48 horas (já incluindo o trabalho extraordinário), pelo que $41 \%$ da nossa amostra encontrase numa situação de "excesso de carga horária semanal".

A existência de cerca de $30 \%$ de médicos que, quando questionados sobre o limite máximo de carga horária semanal a partir do qual consideram haver um claro prejuízo na conciliação trabalho-família, respondem valores iguais ou acima das 50 horas é concordante com o perfil dual reportado sobre a satisfação global com o tema da conciliação trabalho-família; ou seja, é concordante com a existência de dois grandes grupos de respostas quanto à satisfação global com o tema da conciliação trabalho-família: um polarizado na insatisfação $(40,9 \%)$ e outro na satisfação $(34,2 \%)$, como se pode ver na Tabela 2 .

O nível de satisfação é muitas vezes visto como um outcome que se relaciona com a eficácia de uma organização e o desempenho dentro do ambiente de trabalho. ${ }^{27}$ Tem um impacto positivo no nível de intenção de permanecer no trabalho, o que pode ser útil na resolução de problemas de recrutamento e retenção de médicos. ${ }^{28,29} \mathrm{~A}$ satisfação dos médicos inevitavelmente afeta tanto as suas emoções ${ }^{30}$ quanto a conciliação trabalho-família. ${ }^{31}$
Hoje em dia, em alguns países europeus, como a Alemanha, as condições do trabalho clínico para os médicos não têm sido atrativas, pelo que, provavelmente em decorrência disso, um número crescente de médicos alemães decidiu trabalhar em áreas não clínicas (como a indústria farmacêutica, etc.) ou emigrou. ${ }^{32}$ Alguns estudos procuraram investigar os motivos pelos quais os médicos decidiram deixar de trabalhar no setor clínico, investigando por exemplo, o excesso de trabalho, o rendimento insuficiente, etc. Descobrindo que a incompatibilidade entre o trabalho e a vida de família é um dos principais fatores para a insatisfação dos médicos e uma razão nuclear para deixar o trabalho no setor clínico, pelo que outros estudos devem aprofundar a investigação do conflito trabalho-família. ${ }^{33}$

No nosso estudo, as três medidas de conciliação trabaIho-família que os participantes consideraram ser as mais importantes (Fig. 4) foram a possibilidade de flexibilizar o horário, trabalhar a tempo parcial e reduzir temporariamente o horário de trabalho (por exemplo, devido a assistência a família). Estes aspetos poderão eventualmente, explicar as diferenças encontradas na avaliação da conciliação trabalho-família entre o sector público e o sector privado. Poderá existir alguma 'rigidez' do sector público na flexibilização dos horários, apresentando porventura uma estrutura menos flexível e mais burocratizada. No entanto, a maioria dos entrevistados trabalha em hospitais. Neste contexto, é frequente a obrigação de realizar trabalho na urgência, o que dificulta a possibilidade de flexibilização de horários ou o trabalho a tempo parcial. Uma maior agilidade laboral nos horários irá facilitar a aplicação prática destas medidas.

Este trabalho apresenta algumas limitações, sendo que algumas delas já foram mencionadas anteriormente. Além disso, não foram estudadas algumas variáveis que podem

\section{Classificação das medidas de conciliação trabalho-família (média ponderada)}

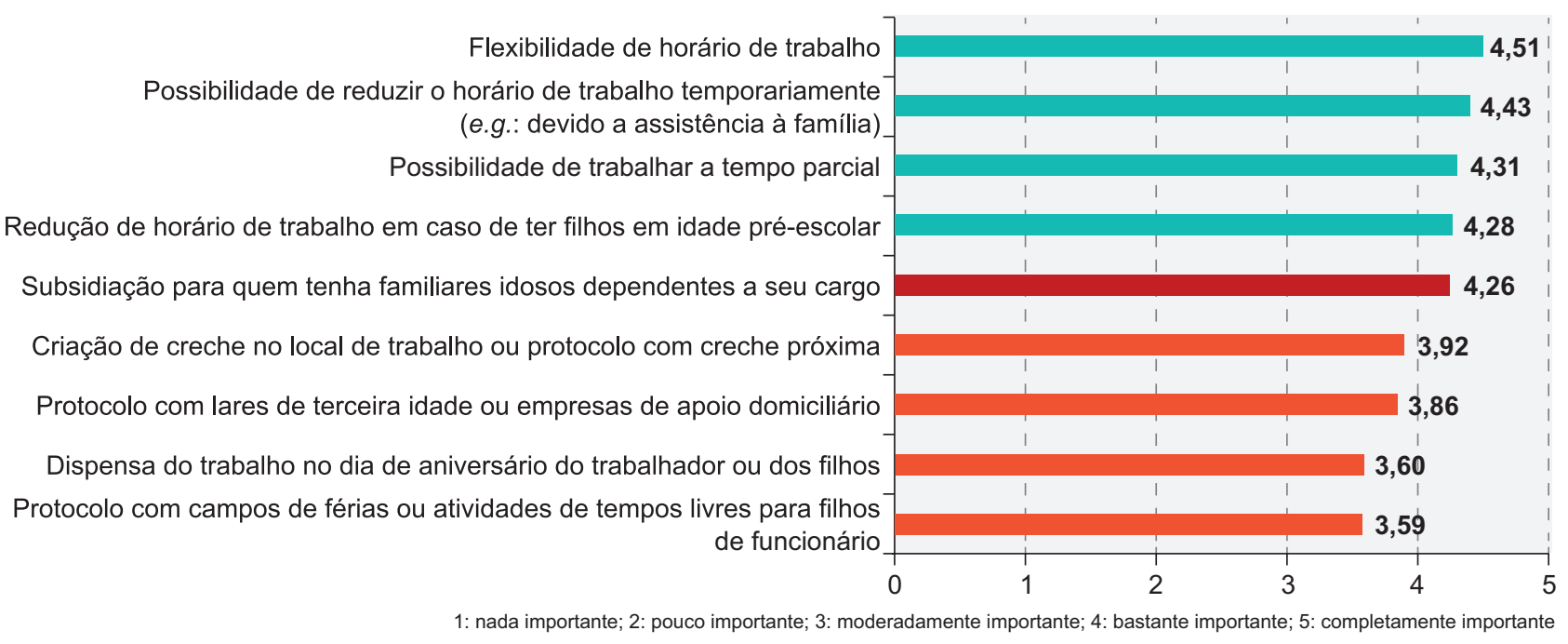

1: nada importante; 2: pouco importante; 3: moderadamente importante; 4: bastante importante; 5: completamente importante

Medidas relacionadas com a flexibilidade de regime e de horário

Subsídios para quem tenha idosos dependentes a cargo

Protocolo com creches, lares ou empresas de aopio domiciliário

Figura 4 - Medidas de conciliação trabalho-família 
interferir com a conciliação trabalho-família, nomeadamente a estrutura familiar, as condições de trabalho, motivação, descanso diário, remuneração salarial, etc. Os médicos têm frequentemente associado à sua atividade profissional, para além da atividade clínica, um conjunto de tarefas burocráticas/administrativas. A nossa metodologia não permitiu diferenciar a carga horária despendida em cada uma destas tarefas, o que pode constituir uma limitação do estudo, visto que o grau de insatisfação com a sobrecarga horária pode ser diferente, conforme se trate de um ou outro tipo de trabalho. A percepção do equilíbrio trabalho-família da nossa amostra poderá não corresponder à da restante população médica, pelo que este aspecto pode constituir um eventual viés. Por último, sendo este um estudo transversal, convém não esquecer que a avaliação sobre este tema pode variar significativamente ao longo do tempo, em função das circunstâncias profissionais e sociofamiliares.

\section{CONCLUSÃO}

A profissão médica pelas suas características de exigência, quer ao nível da carga horária, quer ao nível da necessidade de formação contínua, coloca os médicos numa situação particular de risco para alcançarem uma adequada conciliação trabalho-família. Os resultados do nosso estudo apontam para uma insatisfação dessa conciliação, sendo que essa insatisfação é mais marcada no sector público.

Um dos motivos para este descontentamento parece estar relacionado com o excesso de carga horária semanal.

Verificou-se que a maioria dos participantes (56\%) tem uma carga horária superior à que considera danosa à sua conciliação trabalho-família. Encontrou-se uma associação significativa entre a carga horária e realizar serviço de urgência e ser homem. Identificou-se também uma relação não linear forte com a idade.

Apesar do nosso estudo, por falta de algumas variáveis chave, ainda não encontrar uma forte evidência empírica para a influência negativa da carga horária na satisfação

\section{REFERÊNCIAS}

1. Andrade $C$. Trabalho e vida pessoal: exigências, recursos e formas de conciliação. DEDiCA. Rev Educ Humanidades. 2015;8:117-30.

2. Machado MC. A feminização da Medicina. Análise Soc. 2003;38:127-37.

3. Gaspar D, Jesus SN, Cruz JP. Motivação profissional de médicos internos de Medicina Geral e Familiar, em Portugal: estudo de adaptação de um instrumento. Rev Port Saúde Pública. 2010;28:67-78.

4. Ordem dos Médicos. Estatísticas Nacionais. [consultado 2019 abr 07]. Disponível em: https://ordemdosmedicos.pt/estatisticas-nacionais/\#150 5070622-822-9e31b1b1-6d1a.

5. Direção Geral da Saúde. Principais Indicadores da Saúde para Portugal, 2013-2017. [consultado 2019 abr 07]. Disponível em: https://www.dgs. pt/emdestaque/principais-indicadores-da-saude-para-portugal.aspx.

6. Portdata. Base de Dados Portugal Contemporâneo. Número de divórcios por 100 casamentos. [consultado $2018 \mathrm{dez} 26$ ]. Disponívelem: http://www. pordata.pt/Portugal/Número+de+divórcios+por+100+casamentos-531.

7. Hughes DL, Galinsky E. Work experiences and marital interactions: elaborating the complexity of work. J Organ Behav. 1994;15:423-38.

8. Barnett RC, Hyde JS. Women, men, work, and family: an expansionist theory. Am Psychologist. 2001;56:781-96.

9. Edwards J, Rothbard N. Mechanisms linking work and family: clarifying the relationship between work and family constructs. Acad Manage Rev. 2000;25:178-99. global com a conciliação, o facto de as medidas relacionadas com a flexibilidade de regime e de horário serem as mais assinaladas pela nossa amostra como importantes para a conciliação, é sintomático de que essa relação seja verdadeira.

Esperamos que surjam futuramente mais estudos, com uma amostra com maior representatividade e com mais controlo de variáveis, de modo a ser possível generalizar os resultados e procurar identificar algumas medidas que possam ajudar a melhorar a conciliação trabalho-família na profissão médica.

\section{AGRADECIMENTOS}

Agradecemos a Fátima Carioca pela sua colaboração na análise dos resultados.

Agradecemos ainda à direção nacional da Associação dos Médicos Católicos Portugueses (AMCP) a disponibilização dos e-mails dos seus associados para envio do convite para participação neste estudo.

\section{PROTECÇÃO DE PESSOAS E ANIMAIS}

Os autores declaram que os procedimentos seguidos estavam de acordo com os regulamentos estabelecidos pelos responsáveis da Comissão de Investigação Clínica e Ética e de acordo com a Declaração de Helsínquia da Associação Médica Mundial.

\section{CONFIDENCIALIDADE DOS DADOS}

Os autores declaram ter seguido os protocolos do seu centro de trabalho acerca da publicação de dados.

\section{CONFLITOS DE INTERESSE}

Os autores declaram não ter conflitos de interesses relacionados com o presente trabalho.

\section{FONTES DE FINANCIAMENTO}

Este trabalho não recebeu qualquer tipo de suporte financeiro de nenhuma entidade no domínio público ou privado.

10. Grzywacz JG, Blass BL. Work, family, and mental health: testing different models of work family fit. J Marriage Fam. 2003;65:248-61.

11. Flaquer L. Las políticas familiares en una perspectiva comparada. Barcelona: Fundación La Caixa; 2000.

12. Glass J, Simon R, Andersson M. Parenthood and happiness: effects of work-family reconciliation policies in 22 OECD countries. AJS. 2016;122:886-929.

13. Grover SL, Crooker KJ. The impact of family-friendly policies on the organizational attachment of parents and non-parents. Pers Psychol. 1995;48:271-88.

14. Thompson CA, Beauvais LL, Lyness KS. When work-family benefits are not enough: the influence of work-family culture on benefit utilization, organizational attachment, and work-family conflict. J Vocat Behav. 1999;54:392-415.

15. Allen TD. Family-supportive work environments: the role of organizational perceptions. J Vocat Behav. 2001;58:414-35.

16. Landauer J. Bottom-line benefits of work/life programs. HR Focus. 1997;74:3-4.

17. Bloom N, Kretschmer T, Reenen JV. Are family-friendly workplace practices a valuable firm resource? SMJ. 2011;32:343-67.

18. Bruck C, Allen T, Spector P. The relation between work-family conflict and job satisfaction: a Finer-Grainer analysis. J Vocat Behav. 
2002;60:336-53

19. Bernas $\mathrm{KH}$, Major D. Contributors to stress resistance: testing a model of women's work-family conflict. Psychol Women Q. 2000;24:170-8.

20. Afonso P. Work-family confict in medical profession. Acta Med Port. 2018;31:796-8.

21. Greenhaus J, Beutell N. Sources of conflict between work and family roles. Acad Manage Rev. 1985;10:76-88.

22. Mache S, Bernburg M, Vitzthum K, Groneberg DA, Klapp BF, Danzer G. Managing work-family conflict in the medical profession: working conditions and individual resources as related factors. BMJ Open. 2015;5:e006871.

23. Cook C, Heath F, Thompson RL. A meta-analysis of response rates in web- or internet-based surveys. Educ Psychol Meas. 2000;60:821-36.

24. Hammer L, Allen E, Grigsby T. Work-family conflict in dual-earner couples: within-individual and crossover effects of work and family. J Vocat Behav. 1997;50:185-203.

25. Avison WR, Ali J, Walters D. Family structure, stress, and psychological distress: a demonstration of the impact of differential exposure. J Health Soc Behav. 2007;48:301-17.

26. Gibson H. Are part time doctors better doctors? BMJ. 1997;315:7113.

27. Deng S, Yang N, Li S, Wang W, Yan H, Li H. Doctors' job satisfaction and its relationships with doctor-patient relationship and work-family conflict in China: a structural equation modeling. Inquiry. 2018;55:1-1.
28. Wu D, Wang Y, Lam KF, Hesketh T. Health system reforms, violence against doctors and job satisfaction in the medical profession: a crosssectional survey in Zhejiang Province, Eastern China. BMJ Open. 2014;4:e006431.

29. Aldrees T, Al-Eissa S, Badri M, Aljuhayman A, Zamakhshary M. Physician job satisfaction in Saudi Arabia: insights from a tertiary hospital survey. Ann Saudi Med. 2015;35:210-3.

30. Lu Y, Hu XM, Huang XL. The relationship between job satisfaction, work stress, work-family conflict, and turnover intention among physicians in Guangdong, China: a cross-sectional study. BMJ Open. 2017;7:e014894.

31. Colombo L, Zito M, Ghislieri C. Work-to-family influence and social supports: job satisfaction in a north-Italy public health organizationdifferences between medical and administrative staff. G Ital Med Lav Ergon. 2012;34:A25-33.

32. Fuss I, Nubling M, Hasselhorn HM, Schwappach D, Rieger MA. Working conditions and Work-Family Conflict in German hospital physicians: psychosocial and organisational predictors and consequences. BMC Public Health. 2008;8:353

33. Mache S, Bernburg M, Vitzthum K, Groneberg D, Klapp B, Danzer G. Managing work-family conflict in the medical profession: working conditions and individual resources as related factors. BMJ Open. 2015;5:e006871. 